\title{
Apresentação do dossiê Beatriz Ana Loner: Mundos do Trabalho e Pós-Abolição
}

\author{
Fernanda Oliveira da Silva* \\ Melina Kleinert Perussatto* \\ Micaele Irene Scheer ${ }^{* *}$
}

\begin{abstract}
A análise das associações negras mereceu um estudo à parte. Isso porque, em razão do forte preconceito e discriminação que enfrentavam na sociedade, os negros foram obrigados a desenvolver uma rede associativa completa e diferenciada das demais. Eles formaram desde entidades recreativas até entidades de classe, para organizarem-se na luta pelos seus direitos como trabalhadores e de resistência contra o preconceito e a dominação branca. Nesse processo, provaram possuir um alto grau de criatividade e determinação que a simples enunciação de suas entidades deixa entrever. ${ }^{1}$
\end{abstract}

Embora o fragmento disposto acima evoque uma epígrafe, damos início à apresentação explicitando que ele é bem mais que isso. Aquilo que entendemos como a síntese da unidade entre o campo de estudos dos Mundos do Trabalho e aquele que viria a se constituir como campo de estudos sobre as Emancipações e o Pós-Abolição, foi escrito pela pesquisadora e professora que dá nome ao dossiê, Beatriz Ana Loner. O excerto foi retirado de seu livro, "Construção de Classe: operários de Pelotas e Rio Grande, 1888-1930", de 2001, com segunda edição em 2016. O livro é oriundo de sua tese de doutorado, defendida em 1999, junto ao Programa de Pós-Graduação em Sociologia da Universidade Federal do Rio Grande do Sul.

Ao destinar um capítulo para a análise das associações negras, Beatriz Ana Loner enfrentava, a um só tempo, diferentes problemas já consolidados na historiografia brasileira: a compreensão dos significados do trabalho e da construção da classe operária, mas também a atenção às cores dos trabalhadores e as dinâmicas do racismo antinegro entre os trabalhadores. Loner foi sem dúvida uma precursora

Pós-Doutoranda na Universidade do Estado de Santa Catarina. Pós-doutora pela Universidade Federal Rural do Rio de Janeiro. Doutora em História pela Universidade Federal do Rio Grande do Sul. E-mail: feolisilva@gmail.com. ORCID: https://orcid.org/0000-0001-8198-3552.

** Pós-doutoranda na Universidade do Rio dos Sinos. Doutora em História pela Universidade Federal do Rio Grande do Sul. E-mail: melinaperussatto@gmail.com. ORCID: https://orcid.org/0000-00019356-5956.

*** Doutoranda na Universidade Federal do Rio Grande do Sul. E-mail: scheermica@gmail.com. ORCID: https://orcid.org/0000-0003-0465-2906.

1 LONER, Beatriz Ana. Construção de classe: operários de Pelotas e Rio Grande, 1888-1930. 2. ed. Editora da UFPel: Pelotas, 2016. p. 167. 
ao perceber que esses problemas deveriam ser enfrentados em conjunto, sobretudo ao investigar um tempo histórico imediato à abolição da escravidão. Enfrentamento que Beatriz manteve em toda sua vasta produção e atuação profissional. ${ }^{2}$

Um registro mais recente de seu compromisso historiográfico e político foi registrado nas considerações finais de um artigo coletivo publicado na Revista Mundos do Trabalho em 2013:

O objetivo desses estudos, em nosso entender, é o de, em alguns anos, se ter uma ideia melhor de como homens e mulheres negros, libertos do fantasma da reescravização e de suas consequências a partir de 1888 (e apesar de tudo o que se possa falar da precariedade da liberdade nos "tempos modernos" do capitalismo) lutaram para viver e adaptar-se às novas condições de vida. Ao longo das décadas da Primeira República, algumas vezes venceram, na maioria dos casos foram empurrados para trás, pela sina do operariado no Brasil e pela frustrante e presente discriminação racial que sempre os atingiu. Mas, ao fim e ao cabo, não foram pobres coitados, incapazes de viver por si mesmos. Buscaram oportunidades e empregos, aproveitaram ocasiões e padrinhos, lutaram e militaram, alguns, nas sociedades operárias. Milhares se conformaram, alguns tiveram momentos de glória, outros reconheceram-se derrotados. Mas, enfim, sempre tentaram melhorar de vida, tal como os brancos, tal como o operariado comum. Para não deixar de citar Thompson, mesmo que na última frase, nesse sentido, não precisam da comiseração ou condescendência de nossa parte, precisam é de mais estudos. ${ }^{3}$

Assim, o presente dossiê tem o objetivo de homenagear Beatriz Ana Loner e debater a agenda de pesquisa que ela ajudou a construir. Falecida em 29 de março de 2018, a historiadora foi uma das fundadoras do GT e da Revista Mundos do Trabalho, bem como do GT Emancipações e Pós-Abolição, ambos da Associação Nacional de História (ANPUH-Brasil). Sua produção ressalta a importância de pesquisas atentas às articulações entre classe e raça, com destaque para o trabalhador negro, conforme registrado em seu livro "Construção de classe" e em outras produções. Integram o dossiê, contribuições balizadas na trajetória intelectual da homenageada e em sua agenda de pesquisa, que versa sobre associativismo negro; campesinato negro; movimentos abolicionista e operário; imprensas operária e negra; trajetórias individuais e coletivas; experiências de escravidão e liberdade em perspectiva

Artigos de BeatrizAna Loner, inéditos ou publicados, foram compilados em: GILL, Lorena; KOSHIER, Paulo (orgs). A família Silva Santos e outros escritos: escravidão e pós-abolição ao sul do Brasil. Casa Leiria: São Leopoldo, 2019. Disponível em: https://wp.ufpel.edu.br/ndh/files/2019/06/ familiasilvasantos.pdf. Acesso em: 7 dez. 2019. A organização integra o projeto "Afrodescendentes na região Sul: biografias, trajetórias associativas e familiares" (CAPES, Edital Memórias Brasileiras - Biografias), uma parceria entre UFPel, UFSC e UFPR, que contou com Loner em suas primeiras etapas.

3 LONER, Beatriz Ana; CUNHA FILHO, Miguel Angelo Vieira da; MONTEIRO, Ubirajara Soares Monteiro. De escravo a doutor: Euzébio de Queiroz Coutinho Barcellos. Revista Mundos do Trabalho, v. 5, n. 9, p. 189-213, jan./jun., 2013. Disponível em: https://periodicos.ufsc.br/index.php/ mundosdotrabalho/article/view/1984-9222.2013v5n9p189/25483. Acesso em: 7 dez. 2019. 
histórica; acervos e fontes; questões teóricas, conceituais e metodológicas na história social do trabalho e no campo das emancipações e do pós-abolição, dentre outros.

Paulo Koschier abre o dossiê apresentando um dos arquivos do Núcleo de Documentação Histórica da Universidade Federal de Pelotas (NDH/UFPel). Espaço de ensino, extensão e pesquisa, o NDH foi criado pela professora Beatriz Ana Loner em 1990 e hoje leva o seu nome. É responsável pela preservação de acervos vinculados à história do trabalho e dos trabalhadores, subsidiando diversas pesquisas de graduação e pós-graduação. Koshier aborda em seu artigo o recém-elaborado guia do acervo da Justiça do Trabalho de Pelotas, entre 1936 e 1998, e suas fontes, que somam 93.845 processos.

No artigo seguinte, Aristeu Elisandro Machado Lopes analisa as fotografias $3 \times 4$ dos trabalhadores negros que solicitaram carteira profissional no município de Pelotas/RS, entre os anos de 1933 e 1944. A fonte compõe o acervo da Delegacia Regional do Trabalho do Rio Grande do Sul do NDH/UFPel, constituído por 627 mil fichas de qualificação profissional. Lopes foi bolsista de graduação de Loner, tornou-se seu colega no Departamento de História e recebeu da antiga orientadora a incumbência de cuidar desse acervo após sua aposentadoria, ocorrida em 2011. $\mathrm{O}$ artigo demonstra a potencialidade do uso de fotografia de trabalhadores negros para o estudo sobre a história desses homens e mulheres nas primeiras décadas do século $X X$.

Lorena Almeida Gill é a atual coordenadora no NDH/UFPel - Professora Beatriz Loner. Colega e amiga da homenageada, nos apresenta resultados de uma nova fase do projeto intitulado "À Beira da Extinção", inicialmente coordenado por ambas. Há dez anos, o projeto desenvolve pesquisas sobre ofícios que se transformaram ou que foram extintos. Por meio de narrativas orais, o artigo discute as mudanças laborais dos pescadores e das pescadoras profissionais artesanais que ainda atuam próximo à Laguna dos Patos, Pelotas/RS.

Sem se afastar muito da região mais ao sul do estado gaúcho e margeando a Laguna dos Patos, Cláudia Daiane Garcia Molet analisa as experiências de mulheres negras de oito comunidades remanescentes quilombolas no Litoral Negro (estreita faixa de terra entre a Laguna dos Patos e o Oceano Atlântico). Em seu artigo, Molet destaca os arranjos familiares marcados pela matrilinearidade, as memórias da escravidão e as experiências das personagens estudadas no Pós-Abolição.

Lúcia Helena Oliveira Silva e Regina Célia Lima Xavier foram parceiras de Beatriz Loner no Grupo de Pesquisas "A experiência dos africanos e seus descendentes no Brasil Meridional", responsável pelo "Encontro Escravidão e Liberdade no Brasil Meridional", evento bianual surgido em 2005. As autoras nos oferecem um balanço 
sobre as pesquisas acerca do associativismo negro no Pós-Abolição, com destaque aos avanços registrados e ao trabalho realizado por nossa homenageada.

Paulo Roberto Staudt Moreira, em um recuo temporal, nos brinda com um estudo sobre associativismo negro no contexto escravista. Para tanto, utiliza especialmente documentos judiciais sobre a Sociedade Beneficente Cultural Floresta Aurora, de Porto Alegre, e investe no estudo de trajetória de alguns integrantes da agremiação. Moreira mobiliza a noção de racialização, cara aos estudos sobre o pós-abolição, para compreender a agência dos sujeitos estudados, suas reivindicações políticas e morais, contribuindo para os debates sobre associativismo, liberdade e cidadania negra no século XIX.

Por fim, o artigo de Fernando Pureza, em um debate ampliado sobre a História Social do Trabalho, enfrenta o desafio de colocar em diálogo E.P. Thompson e Angela Davis. Dentre suas intenções, busca oferecer "um olhar mais sensível para as diferentes relações sociais de dominação e resistência no capitalismo". Segundo Pureza, a Bia, como carinhosamente nossa homenageada era conhecida, certamente seria uma de suas leitoras mais críticas e uma das maiores entusiastas do debate proposto.

Em seus trânsitos entre os Mundos do Trabalho e as Emancipações e o Pós-Abolição, Beatriz Ana Loner mostrou o valor do bom debate, tornando-se a expressão de uma intelectual comprometida com o rigor acadêmico, com a pesquisa engajada e com as questões políticas e sociais de seu tempo. Ao agradecermos as contribuições enviadas, convidamos quem as lê, ao estilo Bia, que se disponha não apenas ao bom debate, mas a uma reflexão mais profunda e crítica sobre os avanços, desafios e possibilidades vindos das articulações entre campos. Que a vivacidade de sua obra nos conduza a novos estudos e que sirva sempre como uma sinalização de que a história também é vivida nas batalhas do presente. 